\title{
Gating and Braking of Short- and Long-Term Modulatory Effects by Interactions between Colocalized Neuromodulators
}

\author{
Erik Svensson, Sten Grillner, and David Parker \\ Nobel Institute for Neurophysiology, Department of Neuroscience, Karolinska Institute, S-17177, Stockholm, Sweden
}

Spinal locomotor networks in the lamprey are modulated by tachykinin neuropeptides. A single $10 \mathrm{~min}$ application of the tachykinin substance $P$ evokes a short-term $(\sim 1 \mathrm{hr})$ presynaptic facilitation of glutamate release and the postsynaptic potentiation of NMDA responses. The latter effect induces a long-term (>24 hr) protein synthesis-dependent increase in the frequency of network activity. Tachykinins are contained in a ventromedial spinal plexus into which the medial dendrites of network neurons project. Neurons in this plexus also contain colocalized dopamine and 5-HT. Here, dynamic plasticity evoked by modulator interactions has been examined by investigating the effects of 5-HT and dopamine on specific cellular, synaptic, and network effects of substance P.

Preapplied 5-HT blocked the substance P-mediated increase in the network burst frequency and the potentiation of NMDAevoked cellular responses that underlies its induction. 5-HT also blocked the presynaptic facilitation of glutamatergic syn-

Neuromodulation has been studied extensively (for review, see Harris-Warrick and Marder, 1991; Sillar et al., 1997; Katz, 1999). Although neuromodulators are often examined individually, the abundance of putative neuromodulators in the nervous system, and their corelease or simultaneous release, could provide the opportunity for them to interact (Kupfermann, 1991; Brezina and Weiss, 1997). Even when modulator release is temporally or spatially independent, the modulatory tone resulting from their relatively slow effects could also allow for interactions between modulators (Kupfermann, 1991; Wood, 1995; Brezina and Weiss, 1997; Ayali and Harris-Warrick, 1998; Parker, 2000).

In analogy to the higher-order effects resulting from interactions between activity-dependent synaptic plasticity ("metaplasticity"; Abraham and Bear, 1996), interactions between neuromodulators have been termed recently "metamodulation" (Katz and Edwards, 1999). The complexity that could result from these interactions is daunting, because they potentially make neuromodulation both plastic and modulatory. An understanding of these interactions is thus an important component to our knowledge of nervous system plasticity.

The modulatory effects of the tachykinin neuropeptide substance $\mathrm{P}$ have been examined in the lamprey spinal cord (Parker,

Received March 27, 2001; revised May 24, 2001; accepted June 4, 2001.

This work was supported by grants from the Wellcome Trust, the Swedish Medical Research Council (3026 and 12589), the Science Research Council, and The Wallenberg Foundation. We thank Tom Matheson, Peter Wallén, Abdel El Manira, and Josh Woolley for their comments on this manuscript.

Correspondence should be addressed to David Parker, University of Cambridge, Department of Zoology, Downing Street, Cambridge, CB2 3EJ UK. E-mail: djp27@cam.ac.uk.

Copyright (C) 2001 Society for Neuroscience $\quad 0270-6474 / 01 / 215984-09 \$ 15.00 / 0$ aptic transmission by substance P. The presynaptic, but not postsynaptic, effect of 5-HT was reduced by the protein phosphatase 2B inhibitor cypermethrin.

Dopamine did not directly modulate the effects of substance P. However, it reduced the presynaptic interactive effect of 5-HT and thus gated the presynaptic potentiation of glutamatergic inputs by substance P. However, the substance P-mediated potentiation of NMDA responses was not gated by dopamine, and thus the long-term network modulation was not induced.

Neuromodulator effects and their interactions can thus be modulated. By selecting components from the modulatory repertoire of substance $\mathrm{P}$, these interactions evoke dynamic changes in short- and long-term synaptic and network plasticity.

Key words: metamodulation; spinal cord; lamprey; neuropeptide; substance P; 5-HT; dopamine
2001). Tachykinins are contained in primary afferents and interneurons in the dorsal horn (Van Dongen et al., 1986) (E. Svensson, unpublished observations) and in a ventromedial spinal plexus that also contains colocalized 5-HT and dopamine (Schotland et al., 1996). The medial dendrites of locomotor network neurons project into this plexus, placing these modulators in a position to influence network activity.

The individual network effects of substance P, 5-HT, and dopamine have been examined. Substance $\mathrm{P}$ evokes a long-term $(>24 \mathrm{hr})$ protein synthesis-dependent increase in the frequency of network activity. At the cellular and synaptic level, it modulates the excitability of spinal neurons, presynaptically facilitates glutamate release, and postsynaptically potentiates NMDA responses. The latter effect underlies the induction, but not maintenance, of the long-term burst frequency modulation (for review, see Parker, 2001). 5-HT reversibly reduces the frequency of network activity (Harris-Warrick and Cohen, 1985). At the cellular level, it reduces the calcium-dependent afterhyperpolarization after the action potential (Wallén et al., 1989) and also modulates glutamatergic and glycinergic synaptic transmission (Parker, 2001). Finally, dopamine modulates several cellular and synaptic properties (Schotland et al., 1995; Kemnitz, 1997) and has concentration-dependent effects on the network output (McPherson and Kemnitz, 1994).

The location and proposed paracrinic release of these three modulators in the ventromedial plexus (Christenson et al., 1990; Schotland et al., 1996) provide appropriate conditions for their interactions. The information available on the specific cellular and synaptic effects of substance P (Parker, 2001) allowed these interactions to be examined by investigating the influence of 
5-HT and dopamine on the substance P-evoked modulation. The results show that individual modulatory effects can be modulated (metamodulation; Katz and Edwards, 1999) and that these metamodulatory interactions are also subject to modulation. These interactions select from the distributed effects of substance P to evoke dynamic synaptic and network plasticity.

\section{MATERIALS AND METHODS}

The results presented here were obtained from experiments performed on adult male and female Lampetra fluviatilis. The effects were also seen in Petromyzon marinus. No obvious species or sex differences were apparent in these animals. However, the effects did not occur in preliminary experiments on Icthyomyzon unicupsis $(n=3)$ (D. Parker and E. Svensson, unpublished observations), suggesting a potential species difference in modulator interactions.

Animals were anesthetized with tricaine methanesulphonate (MS-222; Sandoz, Basel, Switzerland). The spinal cord and notochord were removed and placed in a Sylgard-lined chamber (volume of $\sim 2.5 \mathrm{ml}$; Sikema, Stockholm, Sweden). In experiments examining cellular and synaptic modulation, the spinal cord was isolated from the notochord and placed ventral side up in the chamber. In all experiments, the spinal cord was superfused with Ringer's solution containing (in $\mathrm{mM}$ ): $138 \mathrm{NaCl}, 2.1$ $\mathrm{KCl}, 1.8 \mathrm{CaCl}_{2}, 1.2 \mathrm{MgCl}_{2}, 4$ glucose, 2 HEPES, and 0.5 L-glutamine, which was bubbled with $\mathrm{O}_{2}$. The experimental chamber was kept at a temperature of $8-12^{\circ} \mathrm{C}$.

Locomotor activity was evoked by applying NMDA $(50-200 \mu \mathrm{M})$ to the Ringer's solution. The resulting network output was monitored by recording extracellularly from ventral roots on both sides of the spinal cord using glass suction electrodes. Drugs were only applied after the NMDA-evoked network activity was constant, which could take up to 4 $\mathrm{hr}$. Intracellular recordings were made from the cell bodies of spinal cord neurons using thin-walled micropipettes filled with $3 \mathrm{~m}$ potassium acetate and $0.1 \mathrm{~m}$ potassium chloride. Because glutamatergic inputs appear to be relevant to the network effects of substance P (Parker, 2001), glutamatergic synaptic transmission was examined in detail by making paired recordings from excitatory network interneurons (EINs) and motor neurons. Motor neurons were identified by recording orthodromic extracellular spikes in the associated ventral root after current injection in their somata, and EINs by their ability to elicit monosynaptic EPSPs in motor neurons (Buchanan, 1993). EPSPs were identified as monosynaptic if they occurred reliably and with constant latency after presynaptic stimulation at $20 \mathrm{~Hz}$. An Axoclamp 2A amplifier (Axon Instruments, Foster City, CA) was used for voltage recording and current injection. In all cellular experiments, the membrane potential in control and in the presence of drugs was kept constant by injecting depolarizing or hyperpolarizing current using single-electrode discontinuous current clamp. Data were acquired, stored, and analyzed on computer using an analogto-digital interface (Digidata 1200; Axon Instruments) and Axon Instruments software (Axotape and pClamp 6).

Drugs were usually applied to the bath using a peristaltic pump (flow rate of $\sim 0.5 \mathrm{ml} / \mathrm{min}$ ). Cellular responses to NMDA were elicited by pressure applying NMDA $(1 \mathrm{mM})$ from a micropipette onto the surface of the spinal cord above the neuron being recorded from. Because the spinal cord is thin, drugs applied in this way readily gain access to the cell bodies and dendrites of spinal neurons (Wald and Selzer, 1981). Pressure pulse durations of $20-200 \mathrm{msec}$ were given every $60 \mathrm{sec}$ to prevent desensitization, the duration varying in different experiments to give clear, consistent NMDA responses. TTX $(1.5 \mu \mathrm{M})$ was bath applied in all pressure application experiments to block indirect effects attributable to the action of NMDA on nearby neurons.

Membrane potential oscillations were evoked in motor neurons and network interneurons by rapid perfusion $(\sim 5 \mathrm{ml} / \mathrm{min})$ of $1 \mu \mathrm{M}$ substance $\mathrm{P}$ for $1 \mathrm{~min}$. The oscillations were evoked at $1 \mathrm{hr}$ intervals to avoid desensitization (Svensson et al., 1997). They were quantified by measuring the duration of the oscillation episode (i.e., the time from the first to the last depolarizing plateau).

Modulator interactions were examined by applying a second modulator when the effects of the first modulator had stabilized. Unless stated otherwise, $1 \mu \mathrm{M}$ substance $\mathrm{P}$ was applied for $10 \mathrm{~min}$ in all experiments, because this treatment evokes long-lasting ( $>24 \mathrm{hr}$ ) modulation of the locomotor network (Parker et al., 1998). The substance P-mediated modulation took up to $2-3 \mathrm{hr}$ to stabilize (Parker et al., 1998). Once it had stabilized (defined as a constant burst frequency over a continuous $30 \mathrm{~min}$ period), 5-HT or dopamine were applied for $10 \mathrm{~min}$ to see whether they evoked their usual network effects (Harris-Warrick and Cohen, 1985; McPherson and Kemnitz, 1994). Because 5-HT and dopamine do not have long-term effects on the network output, their influence on the cellular and network effects of substance P was examined by applying them continuously. Cypermethrin, okadaic acid (OA), and phorbol 12,13 dibutyrate (PDBu) were dissolved in DMSO. The final concentration used was $10 \mu \mathrm{M}$, which gave a final DMSO concentration of $0.01-0.1 \%$. In control experiments, this concentration does not affect NMDA-evoked network activity (Parker et al., 1998).

Statistical significance was examined using two-tailed paired or independent $t$ tests, or one-way ANOVA. All experiments that investigated a particular treatment or effect were included in the statistical analysis whether an effect was seen or not. A lack of significance reflects the failure of a modulator to evoke an effect in the presence of other modulators. $n$ numbers in the text refer to the number of experiments performed. All values given refer to mean \pm SEM. Only one experiment was performed in each piece of spinal cord, with no more than two pieces of cord being taken from the same animal.

\section{RESULTS}

The individual effects of 5-HT, dopamine, and substance P on the output of the lamprey locomotor network have been examined previously (see introductory remarks). Here, the interactive effects of these modulators have been examined.

\section{The interactive effects of 5-HT and substance $P$ on NMDA-evoked network activity}

The interactive effects of 5-HT and substance P were initially examined on NMDA-evoked locomotor network activity. In the absence of 5-HT, substance P (1 $\mu \mathrm{M}$ for $10 \mathrm{~min}$ ) consistently resulted in a long-term $(>10 \mathrm{hr})$ increase in the frequency of NMDA-evoked ventral root bursts ( $n=7$ of 7 ) (Fig. $1 A, B)$ (Parker et al., 1998). However, there was no significant increase in the burst frequency when substance $\mathrm{P}$ was applied in the presence of 1 or $10 \mu \mathrm{M} 5$-HT $(n=11$ of 12 ; substance P in 5-HT, $p>0.1$, $n=12$ ) (Fig. $1 A, B)$. 5-HT alone reduced the frequency of NMDA-evoked ventral root bursts from a control frequency of $1.7 \pm 0.4 \mathrm{~Hz}$ to either $1.0 \pm 0.2 \mathrm{~Hz}(1 \mu \mathrm{M} ; n=12)$ or $0.6 \pm 0.1$ $\mathrm{Hz}(10 \mu \mathrm{M} ; n=12$; data not shown) (Harris-Warrick and Cohen, 1985). This direct effect of 5-HT on the burst frequency cannot account for the inhibition of the substance P-mediated network modulation, because the effects of substance $\mathrm{P}$ are greater from lower initial burst frequencies (Parker et al., 1998).

When 5-HT (10 $\mu \mathrm{M})$ was applied $4 \mathrm{hr}$ after substance P (i.e., at a time when the substance P-mediated increase in burst frequency had stabilized), the burst frequency was reduced from $3.5 \pm 0.4$ to $1.5 \pm 0.4 \mathrm{~Hz}(n=4$; data not shown). This reduction $(43 \%)$ is similar to that evoked by 5 -HT in the absence of the substance P-mediated modulation (35\%). The network effects of substance $\mathrm{P}$ thus did not influence the 5-HT-mediated network modulation.

The long-term substance P-mediated burst frequency modulation has a protein kinase $\mathrm{C}$ (PKC)-dependent induction phase that lasts for 2-3 hr after substance P application (Parker et al., 1998), which is followed by a protein synthesis-dependent maintenance phase (Parker, 2001). To determine whether 5-HT could affect both the induction and the maintenance of the burst frequency modulation, it was applied at different times after substance P wash-off (Fig. 1C). 5-HT blocked or reversed the burst frequency modulation when it was applied up to $1 \mathrm{hr}$ after substance $\mathrm{P}(n=4$ of 5 ; substance $\mathrm{P}$ in 5-HT, $p>0.1)$. The effects of 5-HT were more variable when it was applied 1-2 hr after substance $\mathrm{P}$, reversal of the burst frequency modulation occurring in three of seven experiments $(p>0.1)$. Although 5-HT reduced the burst frequency when it was applied $>2 \mathrm{hr}$ after substance $\mathrm{P}$, on wash-out of 5-HT, the burst frequency returned to the pre- 
Ai

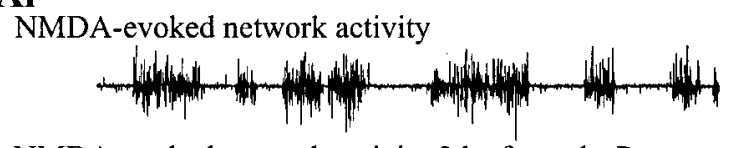

NMDA-evoked network activity $2 \mathrm{~h}$ after subs $\mathrm{P}$

Aii

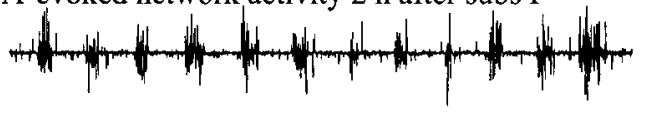

NMDA + 5-HT-evoked network activity

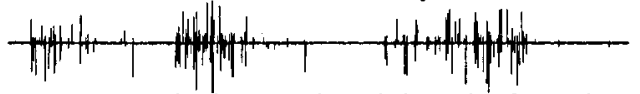

NMDA + 5-HT-evoked network activity $2 \mathrm{~h}$ after subs $\mathrm{P}$

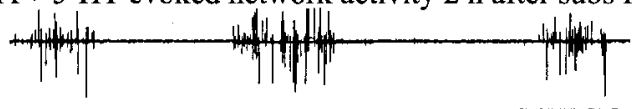

B

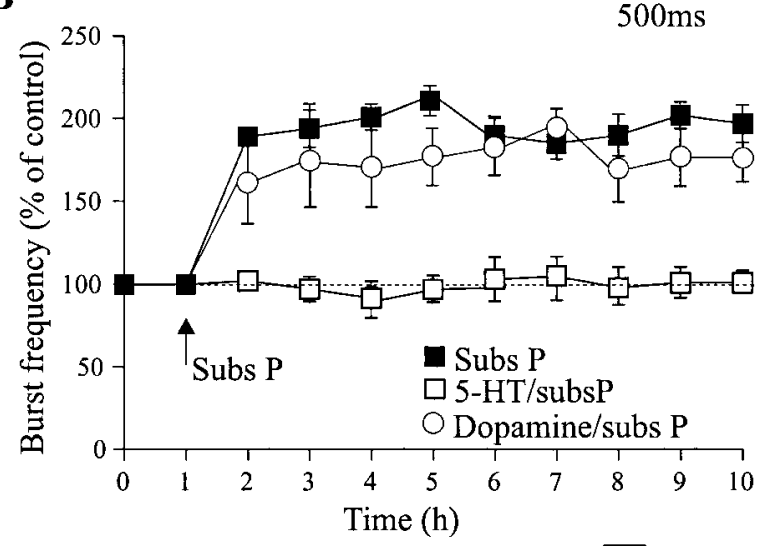

C

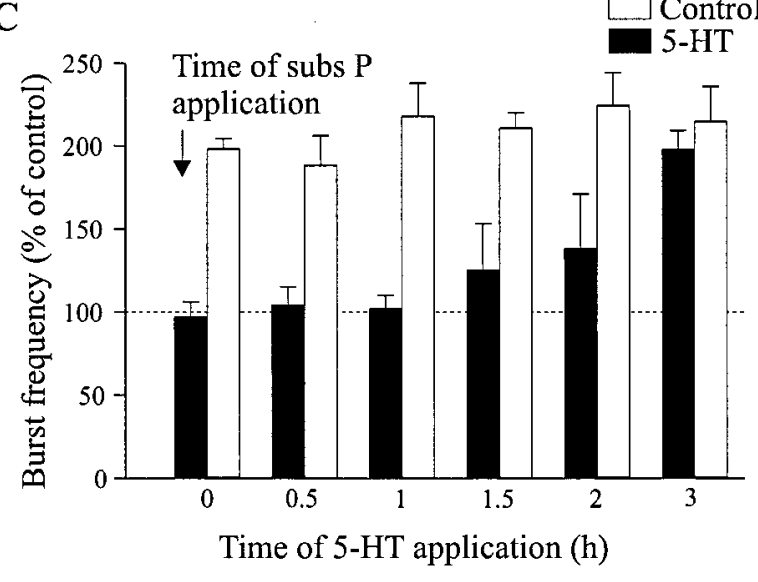

Figure 1. The interactive effects of 5-HT and dopamine on the substance P-mediated network modulation. $A$, Traces showing ventral root activity evoked by NMDA $(50 \mu \mathrm{M})$ on one side of the spinal cord in the absence of substance $\mathrm{P}$ and $2 \mathrm{hr}$ after substance $\mathrm{P}$ application $(1 \mu \mathrm{M}$ applied for 10 min). Traces show the effects of substance $P$ when applied in the absence (Ai) or presence $(A i i)$ of 5-HT $(1 \mu \mathrm{M})$. B, Graph summarizing the independent effects of substance $\mathrm{P}(1 \mu \mathrm{M}$ for $10 \mathrm{~min}$; black arrow) on NMDA-evoked ventral root bursts $(\square)$ and the interactive effects of preapplied 5-HT (1-10 $\mu \mathrm{M} ; \square ; 5-H T / s u b s P)$ or dopamine (1-100 $\mu \mathrm{M}$; $\bigcirc$; Dopamine/subs $P$ ) on the substance P-evoked modulation. $C$, Graph summarizing the effects of 5-HT on the induction and maintenance of the long-term substance P-mediated network modulation. 5-HT was either applied simultaneously with substance $\mathrm{P}$ (time 0 ) or at varying times after the start of substance P wash-off. The network modulation was blocked or reversed when 5 -HT was applied $<1 \mathrm{hr}$ after substance $\mathrm{P}$, but not when it was applied $>2 \mathrm{hr}$ after substance $\mathrm{P}$, i.e., when the protein synthesisdependent maintenance phase had begun (Parker, 2001). The burst frequency was measured after washing off 5-HT for $1 \mathrm{hr}$ (i.e., when its direct effects on the burst frequency had recovered). The white bars show the effects of substance P on the burst frequency in the absence of 5-HT.
5-HT potentiated level ( $n=7$ of 7; $p<0.05$ ) (Fig. $1 C$ ). 5-HT thus blocked the induction of the substance P-mediated burst frequency modulation but could not reverse it once the protein synthesis-dependent maintenance phase had begun.

\section{Interactive effects of 5-HT and substance $P$ on glutamatergic synaptic transmission}

In $\sim 70 \%$ of experiments, substance $\mathrm{P}$ potentiates the amplitude of monosynaptic EPSPs evoked by glutamatergic EINs in motor neurons. It also increases both the amplitude and frequency of spontaneous glutamatergic miniature EPSPs, suggesting that it acts presynaptically and postsynaptically to potentiate glutamatergic synaptic transmission (Parker, 2001). Postsynaptically, substance $\mathrm{P}$ specifically modulates NMDA-mediated responses, an effect that induces the long-term burst frequency modulation (Parker, 2001). An inhibitory effect of 5-HT on the modulation of NMDA responses is thus a potential cellular mechanism for the interactive inhibition of the network effects of substance P. 5-HT could either directly inhibit cellular responses to NMDA or, alternatively, could inhibit their potentiation by substance $\mathrm{P}$. These possibilities were examined by recording intracellularly from spinal neurons and investigating the effect of 5-HT on TTX-resistant depolarizations evoked by pressure application of NMDA (see Materials and Methods).

5-HT $(1-10 \mu \mathrm{M})$ did not significantly affect the amplitude of NMDA-evoked depolarizations $(n=14 ; p>0.1)$ (Fig. $2 B)$. However, it usually ( $n=6$ of 9 ) blocked the potentiation of NMDA responses by substance $\mathrm{P}$ (substance $\mathrm{P}$ in 5-HT, $p>0.05$, $n=9$ ) (Fig. $2 A, B$ ). In three experiments, substance $\mathrm{P}$ did potentiate the amplitude of NMDA depolarizations when it was applied in the presence of 5-HT. Although the magnitude of this potentiation $(42 \pm 7 \%)$ matched that evoked by substance $\mathrm{P}$ in the absence of 5-HT $(47 \pm 11 \%)$, its duration was markedly reduced, essentially being limited to the time that substance $\mathrm{P}$ was present in the bath (duration of NMDA potentiation in substance $\mathrm{P}$ alone, $72 \pm 9.5 \mathrm{~min}$; duration in 5-HT and substance P, $10.2 \pm$ $3.5 \mathrm{~min}$ ) (Fig. 2B). This effect of 5 -HT thus provides a potential cellular mechanism for the inhibition of the substance P-mediated network modulation.

Although 5-HT did not directly affect the amplitude of postsynaptic responses to NMDA, it did significantly reduce the amplitude of EIN-evoked EPSPs in motor neurons ( $1 \mu \mathrm{M}, n=5, p<$ $0.05 ; 10 \mu \mathrm{M}, n=8, p<0.01$ ) (Fig. $2 C, D)$. The absence of an effect of 5-HT on postsynaptic responses to pressure-applied NMDA (Fig. 2) or glutamate (Buchanan and Grillner, 1991) suggested that 5-HT presynaptically reduced glutamatergic inputs.

In addition to directly reducing the amplitude of EIN-evoked EPSPs, 5-HT also blocked their potentiation by substance $\mathrm{P}$ ( $n=$ 5 of 5; substance P in 5-HT, $p>0.1$ ) (Fig. $2 C, D$ ). Substance P can potentiate EIN-evoked EPSPs when NMDA receptors are blocked by AP5 (Parker, unpublished observations), presumably through the residual presynaptic facilitating effect. The absence of any synaptic potentiation thus suggested that 5-HT also blocked the substance P-mediated presynaptic facilitating effect.

Evidence in support of a presynaptic inhibitory interaction by 5-HT was obtained by examining its effect on membrane potential oscillations evoked in spinal neurons by brief ( $1 \mathrm{~min})$ applications of substance P. These oscillations are characterized by irregular shifts in membrane potential on which spikes can occur (Fig. 2E). They are blocked by TTX and are thus synaptically generated, presumably as a result of the direct substance P-evoked depolarization of glutamatergic spinal interneurons (Parker and Grillner, 
A
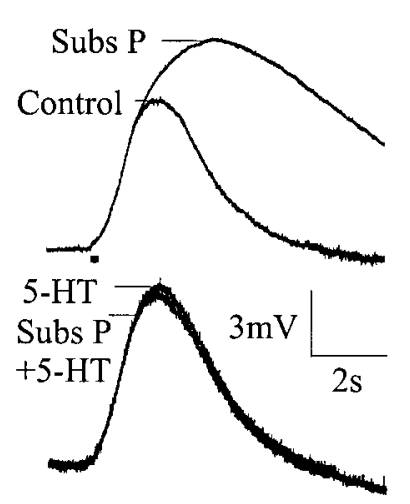

C

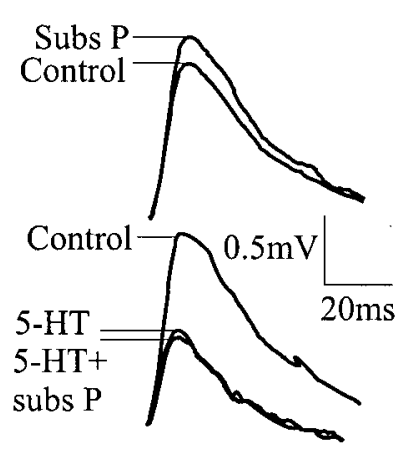

B

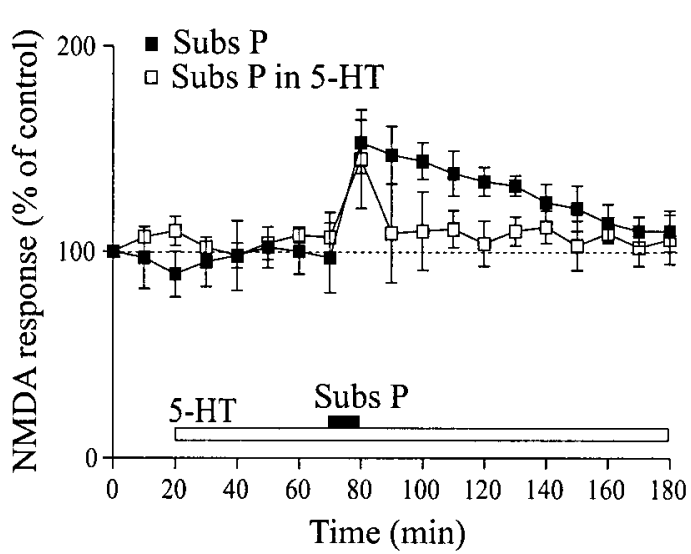

D

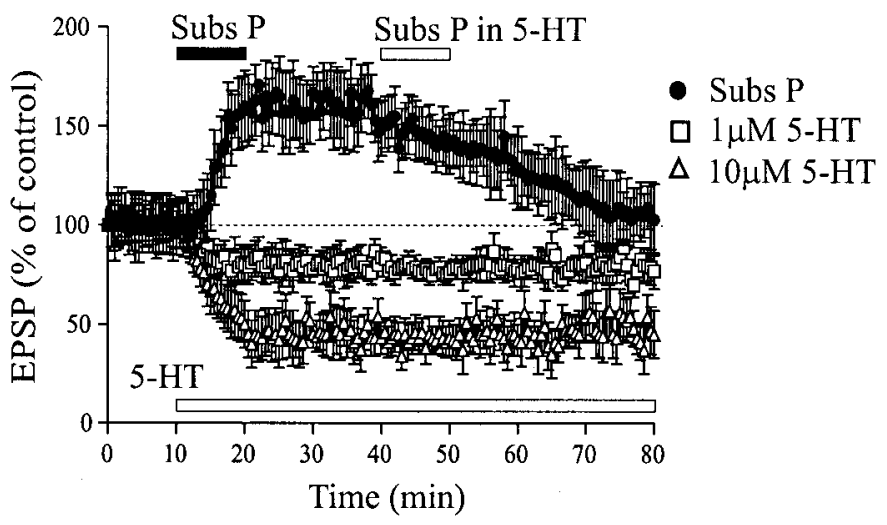

Control

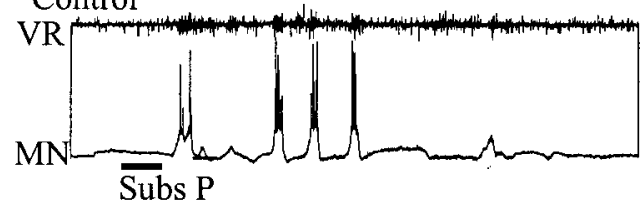

Pre-applied 5-HT

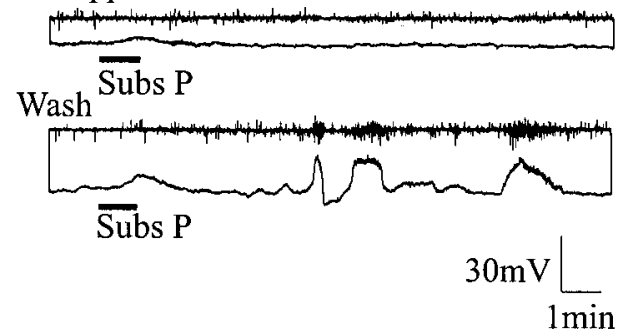

Figure 2. Interactive effects of 5-HT on the substance $\mathrm{P}($ Subs $P$ )-mediated synaptic modulation. $A$, Traces showing the effect of substance $\mathrm{P}$ on depolarizations evoked by pressure application of NMDA in motor neurons in separate experiments in which 5-HT was absent (top traces) or present (bottom traces). Five traces were averaged before and after substance $\mathrm{P}$ application. The black bars below the traces indicate the onset and duration of NMDA application (200 and $100 \mathrm{msec}$ in the top and bottom traces, respectively). TTX was bath applied in all experiments to block indirect effects attributable to the action of NMDA on nearby neurons. The resting membrane potential in the presence of substance P and 5-HT was kept at the control level $(-60 \mathrm{mV})$ by current injection. B, Graph summarizing the modulation of NMDA-evoked depolarizations. 5-HT (10 $\mu \mathrm{M}$; white bar and symbols) alone did not directly affect the amplitude of TTX-resistant NMDA depolarizations in motor neurons. However, 5-HT either blocked the potentiation of NMDA responses by substance $\mathrm{P}$ or reduced the duration of the effect essentially to the time that substance $\mathrm{P}$ was present in the bath. The bars on this and subsequent graphs indicate the onset and duration of modulator application. C, Traces showing the effect of substance P (top traces) and 5-HT and substance P (bottom traces) on EIN-evoked EPSPs. The top and bottom sets of traces are taken from separate experiments. The resting membrane potential in the presence of substance $\mathrm{P}$ and 5-HT was again kept at the control level ( $-65 \mathrm{mV}$ in these experiments) by current injection. $D$, Graph summarizing the independent and interactive effects of substance P and 5-HT on the amplitude of EIN-evoked EPSPs. Substance P potentiates the amplitude of monosynaptic EIN-evoked EPSPs in motor neurons (its application in the absence of 5-HT is indicated by the black bar at the top). 5-HT $(1$ or $10 \mu \mathrm{M})$ concentration-dependently reduced the amplitude of EIN-evoked EPSPs (white bar). When applied in the presence of 5-HT, substance P ( gray bar) did not potentiate the EIN-evoked EPSP. E, Substance P evoked membrane potential oscillations and spiking in motor neurons (MN) and phasic ventral root activity $(V R)$. The oscillations and ventral root activity were reduced or abolished by 5-HT. The oscillations partly recovered on 5-HT wash-off. Black bars indicate substance P application ( $1 \mu \mathrm{M}, 1 \mathrm{~min})$. The membrane potential before substance $\mathrm{P}$ application in control and in the presence of 5 -HT was maintained at $-70 \mathrm{mV}$ by current injection.

1998). The oscillations are reduced or abolished by the nonNMDA receptor antagonist CNQX, but are depressed, but not abolished by the NMDA receptor antagonist AP-5 (Svensson et al., 1997). Substance $P$ does not modulate postsynaptic responses to non-NMDA receptor agonists (Parker et al., 1998). The dependence of the oscillations on non-NMDA receptors, shown by the marked effects of non-NMDA receptor antagonists, thus suggests a significant contribution of the presynaptic facilitation of glutamate release. In the presence of 5-HT $(1-10 \mu \mathrm{M})$, the substance P-mediated oscillations were either abolished $(n=3)$ or the duration of the oscillation episode markedly reduced $(n=$ 7) (Fig. 2E). 5-HT thus mimicked the potent inhibitory effect of non-NMDA receptor antagonists on the oscillations. It also re- duced the duration of the substance P-evoked oscillation episode when NMDA receptors were blocked with the antagonist AP-5 (100 $\mu \mathrm{M} ; n=2$; data not shown), again supporting a presynaptic inhibitory effect. Although other unidentified mechanisms could contribute, these results support an interactive inhibitory effect of 5-HT on the substance P-evoked presynaptic facilitation.

\section{Mechanisms underlying the interactive effects of 5-HT}

Several mechanisms could account for the inhibitory effects resulting from the modulator interactions shown above (Kupfermann, 1991; Katz and Edwards, 1999). Because substance P was applied exogenously, an effect on its release is not applicable here. Other potential mechanisms include an effect of 5-HT on the 
affinity of substance $\mathrm{P}$ for tachykinin receptors, the enhancement of tachykinin breakdown, or an effect on the intracellular pathways activated by substance P. Each of these possibilities was examined.

Because 5-HT did not necessarily block the potentiation of NMDA responses by substance $\mathrm{P}$ but only reduced the duration (Fig. 2B), it seemed unlikely that 5-HT prevented substance P from binding to or activating its receptor. The facilitation of endogenous tachykinin breakdown also appeared unlikely, because the endopeptidase inhibitor phosphoramidon $(2-10 \mu \mathrm{M}) \mathrm{did}$ not block the inhibitory effects of 5-HT on the substance P-evoked network modulation ( $n=4$; data not shown). Phosphoramidon blocks tachykinin breakdown in the lamprey (Parker et al., 1998) and should thus have affected the 5-HT-mediated interactive inhibition if tachykinin breakdown was involved.

Because the above mechanisms apparently cannot account for the inhibition of the substance P-mediated modulation, an effect of 5-HT on the intracellular pathways activated by substance P was examined. The burst frequency modulation and the potentiation of NMDA responses by substance P is PKC dependent (Parker et al., 1998), and preliminary data suggest that its presynaptic facilitating effect is also mediated by PKC (Parker, unpublished observations). An effect of 5-HT on PKC-mediated intracellular pathways was investigated by examining the effect of 5-HT on the potentiation of NMDA-evoked depolarizations by the PKC-activating phorbol ester PDBu $(10 \mu \mathrm{M})$ (Parker et al., 1998). As with substance P, 5-HT prevented any sustained PDBumediated potentiation of NMDA-evoked depolarizations (PDBu in 5-HT, $p>0.1, n=5$ ) (Fig. 3A). 5-HT thus inhibited either the activation of or downstream effects of PKC (Kupfermann 1991; Bhalla and Iyengar, 1999).

The intracellular mechanisms through which 5-HT inhibited the PKC-mediated effects were examined. The intracellular pathways activated by 5-HT in the lamprey are unknown (Wallén et al., 1989). However, the inhibitory effect of 5-HT on the substance $\mathrm{P}$-mediated increase in the burst frequency was not protein kinase A (PKA) or G (PKG) dependent, because the bath application of activators (forskolin, $10 \mu \mathrm{M}, n=4$; Sp-cAMPs, $10 \mu \mathrm{M}, n=4$ ) or inhibitors (H8, $10 \mu \mathrm{M}, n=3$; Rp-cAMPs, $10 \mu \mathrm{M}, n=4$ ) of these intracellular pathways in the lamprey (Parker et al., 1997) did not affect the substance P-mediated burst frequency modulation or its interactive inhibition by 5 -HT (data not shown).

Because 5-HT only affected the duration and not necessarily the peak amplitude of the substance $\mathrm{P}$-mediated potentiation of NMDA responses (Fig. 2B), the PKC-mediated pathway underlying this effect was presumably not necessarily blocked by 5-HT, but the duration of its activation was reduced. An effect of this sort could result from the activation of protein phosphatases that terminate the effects of protein kinases (PPs) (Herzig and Neumann, 2000). The ability of PP antagonists to block the inhibitory interactive effects of 5-HT was thus examined. The PP2B inhibitor cypermethrin $(10-100 \mu \mathrm{M})$ and the PP1 and PP2A inhibitor OA $(10-100 \mu \mathrm{M})$ did not reduce the inhibitory effect of 5-HT on the substance P-mediated network modulation $(n=6$ of 8 ; substance $\mathrm{P}$ in 5-HT and PP antagonists, $p>0.1$ ) or the potentiation of NMDA-evoked depolarizations ( $n=6$ of 6 ; substance $\mathrm{P}$ in 5-HT and PP antagonists, $p>0.1$; data not shown). Activation of these protein phosphatases thus cannot account for the interactive inhibitory effects of 5-HT. However, the PP2B antagonist cypermethrin reduced the effect of 5-HT on the substance $\mathrm{P}$-evoked oscillations and thus resulted in a significant increase in the duration of the oscillation episode (substance P in 5-HT and
A

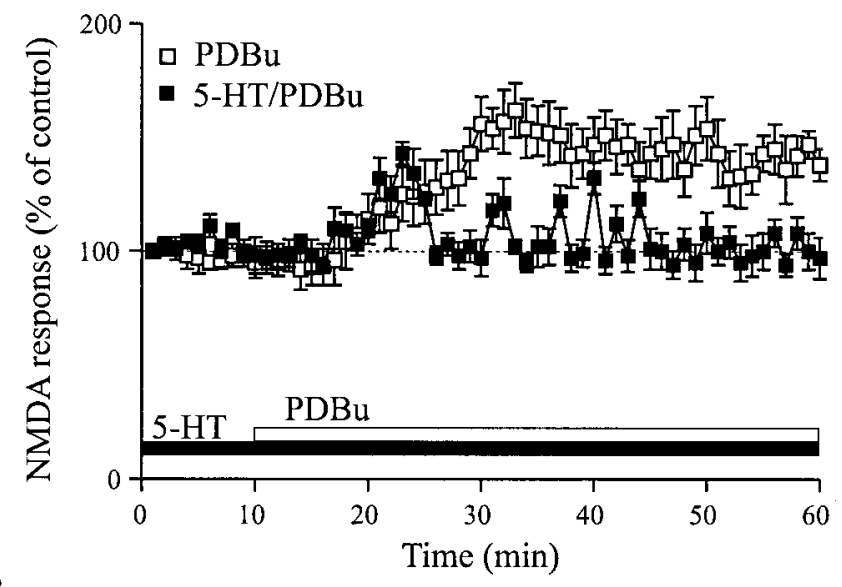

B

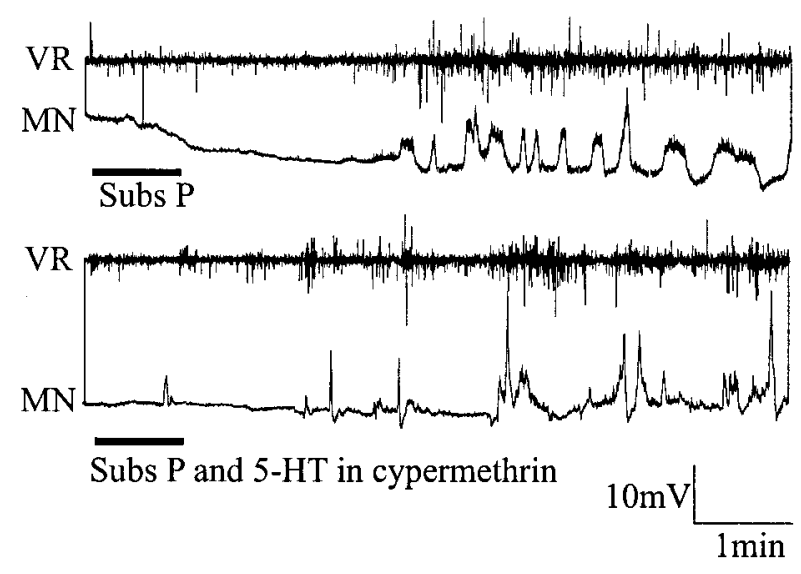

Figure 3. $A, 5$-HT blocks the PDBu-mediated potentiation of NMDA responses. In control, PDBu $(10 \mu \mathrm{M})$ potentiated the amplitude of responses evoked by pressure application of NMDA in the presence of TTX. Notice that no sustained potentiation developed in the presence of 5-HT $(1 \mu \mathrm{M})$. Data from five experiments are shown on the graph. In each case, the membrane potential was kept at the control level ( -60 to -65 $\mathrm{mV}$ ) by current injection. $B$, The inhibition of the substance P (Subs $P$ )-mediated membrane potential oscillations $(M N)$ and ventral root activity $(V R)$ was reduced by the protein phosphatase $2 \mathrm{~B}$ inhibitor cypermethrin (compare with Fig. $2 E$ ). The membrane potential before substance $\mathrm{P}$ application in control and in the presence of cypermethrin and 5 -HT was kept at the control level of $-65 \mathrm{mV}$.

cypermethrin, $p<0.05, n=5$ ) (Fig. 3B). Because cypermethrin did not block the inhibitory effect of 5-HT on the NMDA potentiation, PP2B activation can presumably only account for the presynaptic inhibitory effect of 5-HT.

\section{Effects of dopamine on substance P-mediated modulation}

Dopamine colocalizes with 5-HT in neurons in the ventromedial spinal plexus and has synergistic effects with 5-HT at the cellular and network levels (Schotland et al., 1995). Its effects were thus also examined on the substance P-mediated modulation. Preapplied dopamine (1-100 $\mu \mathrm{M})$, however, did not prevent a significant $(p<0.05)$ effect of substance $\mathrm{P}$ on the network burst frequency $(n=18)$ (Fig. $1 B)$, NMDA-evoked membrane potential depolarizations ( $n=9$; data not shown), EIN-evoked EPSPs $(n=5$ of 5$)$ (Fig. $4 C, D)$, or membrane potential oscillations $(n=4$; data not shown). Dopamine thus did not share the interactive inhibitory effects of 5-HT on the substance P-evoked modulation.

Dopamine $(100 \mu \mathrm{M})$ reduced the frequency of network activity 
A

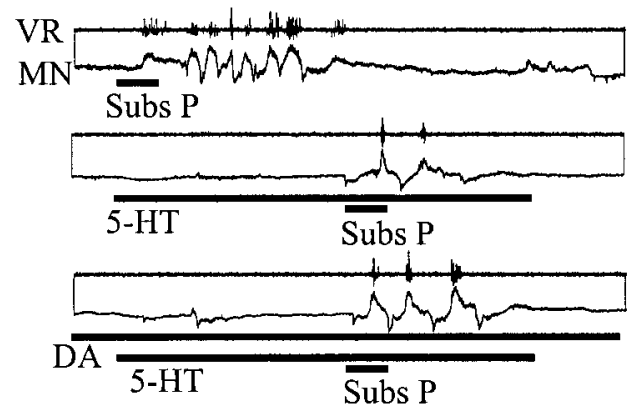

C

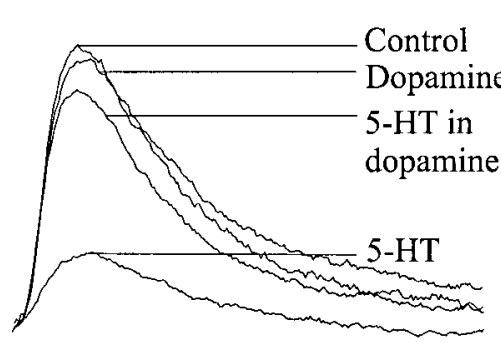

B
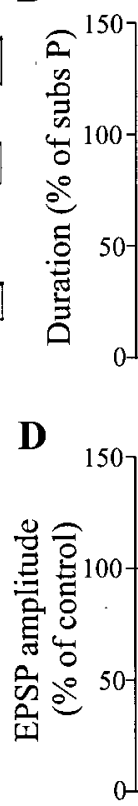

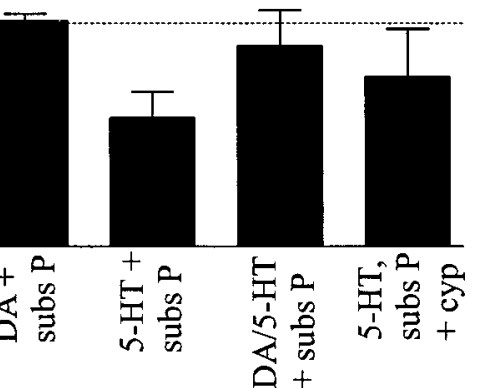

Ei

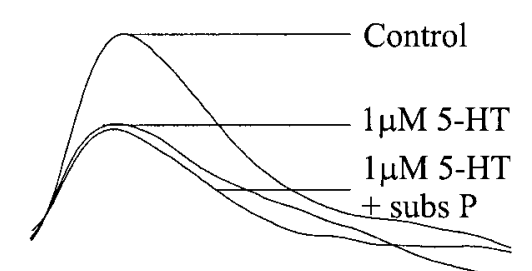

Eii

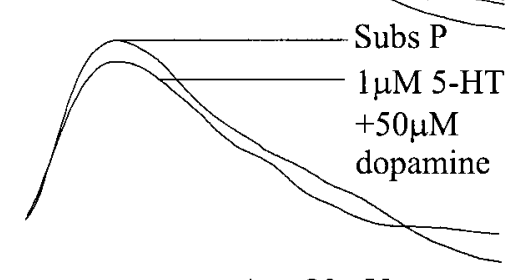

$\begin{array}{cr}\text { A } & 20 \mathrm{mV} \\ \text { C } & 0.5 \mathrm{mV} \\ \text { Ei,Eii } 1 \mathrm{mV}\end{array}$

A 2 min
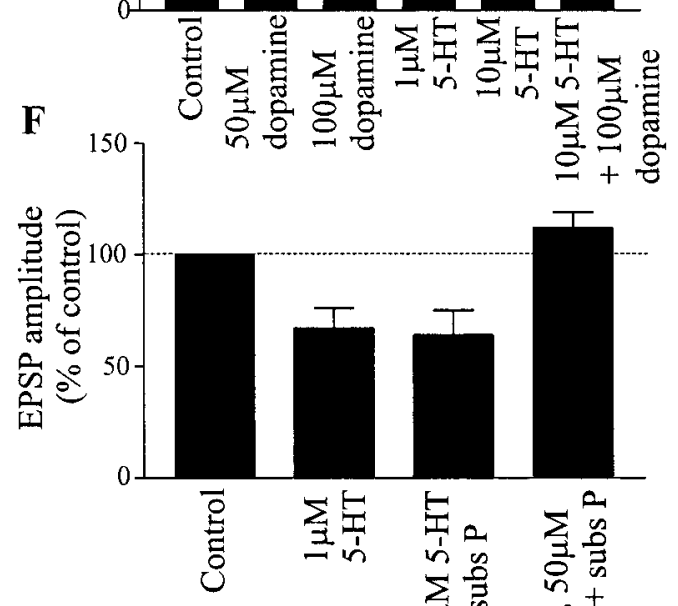
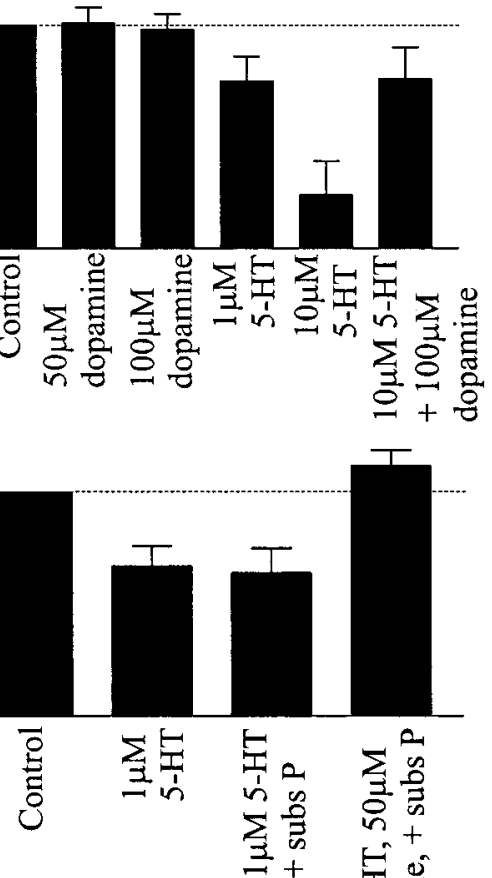

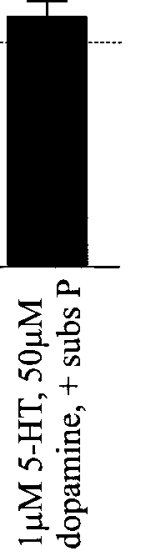

Figure 4. Dopamine reduced the presynaptic inhibitory effects of 5-HT. A, Traces showing oscillations evoked by rapid $1 \mathrm{~min}$ application of substance $\mathrm{P}$ (Subs $P$ ) alone, in the presence of 5-HT, and in the presence of 5-HT and dopamine $(D A)$. The resting membrane potential before substance $\mathrm{P}$ application was kept at the control value $(-76 \mathrm{mV})$ in 5-HT and 5-HT plus dopamine. VR, Ventral root activity; $M N$, motor neurons. $B$, Graph presenting the oscillations as percentage of the duration of the response evoked by substance $\mathrm{P}$ alone. Dopamine $(D A)$ itself did not significantly affect the duration of the oscillations (i.e., the oscillation episode approximately matched that evoked by substance $\mathrm{P}$ alone), but it reduced the inhibitory effect of 5-HT. The PP2B inhibitor cypermethrin (cyp) also reduced the inhibitory effect of 5-HT on the duration of the oscillations. The oscillations require a wash-off time of $1 \mathrm{hr}$ between applications to prevent desensitization. However, rundown does occur over time. The reduction of the oscillations in 5-HT was greater than that after a second substance $\mathrm{P}$ application, and with dopamine, a third application of substance P evoked an enhanced response. Rundown thus cannot account for the effects of 5-HT but may have reduced the magnitude of the gating effect of dopamine. $C$, Traces showing the effect of 5-HT, dopamine, and 5-HT plus dopamine on EIN-evoked EPSPs in a motor neuron. $D$, Graph summarizing the modulation of EIN-evoked EPSPs. Dopamine $(50-100 \mu \mathrm{M})$ did not affect monosynaptic EIN-evoked EPSPs. However, it significantly reduced the direct inhibitory effect of 5-HT (1-10 $\mu \mathrm{M}) . E i$, Traces showing the block of the substance $\mathrm{P}(1 \mu \mathrm{M})$-mediated potentiation of EIN-evoked EPSPs in the presence of 5-HT. Eii, In addition to reducing the direct presynaptic inhibitory effect of 5-HT, dopamine gated the substance P-mediated potentiation of EIN-evoked EPSPs. F, Graph showing the inhibitory effect of 5-HT on the substance P-evoked potentiation of EIN inputs and the
reduction of this effect by dopamine. In all experiments, the membrane potential in the presence of drugs was kept at the control level by current injection.

when it was applied $4 \mathrm{hr}$ after substance $\mathrm{P}(n=5$ of $6 ; p<0.05)$. Its effects on the burst frequency were thus not affected by substance P. The lack of an effect of dopamine on the substance P-mediated modulation and vice versa suggests that exogenously applied dopamine and substance P do not interact directly.

\section{Dopamine gates substance P-mediated synaptic modulation by inhibiting the presynaptic inhibitory effects of 5-HT}

As a final step in the analysis of modulator interactions, the effect of coapplied 5-HT and dopamine on the substance P-mediated synaptic and network modulation was examined. As with 5-HT alone, simultaneous application of 5-HT (1-10 $\mu \mathrm{M})$ and dopamine $(50-100 \mu \mathrm{M})$ blocked any significant effect of substance $\mathrm{P}$ on the network burst frequency $(n=7)$ or NMDA-evoked depolariza- tions $(n=5$; substance $\mathrm{P}$ in 5-HT and dopamine, $p>0.05)$. However, in the presence of both dopamine and 5-HT, substance $\mathrm{P}$ had a significantly greater effect on the duration of the membrane potential oscillation episode than it had in the presence of 5-HT alone $(n=5$ of $6 ; p<0.05)$ (Fig. $4 A, B)$. Because the increased duration of the oscillation episode occurred in the absence of the postsynaptic potentiation of NMDA responses, it presumably reflected the presynaptic facilitatory effect of substance $\mathrm{P}$, suggesting that dopamine reduced the presynaptic 5-HT-mediated inhibitory interaction. This possibility was examined directly by investigating the effect of dopamine on the 5-HT-mediated inhibition of EIN-evoked EPSPs (Fig. 4C,D). In these experiments, dopamine $(10-100 \mu \mathrm{M})$ alone did not significantly affect the amplitude of EIN-evoked EPSPs $(n=9 ; p>0.1)$ 
(Fig. 4C,D). It did, however, reduce the direct inhibitory effect of 5-HT ( $n=9$; 5-HT in dopamine, $p>0.1$ ) (Fig. $4 C, D)$. Dopamine thus blocked the direct presynaptic inhibitory effect of 5-HT on EIN synaptic transmission.

To determine whether dopamine could also block the interactive presynaptic effect of 5-HT, the effect of substance $\mathrm{P}$ on EIN-evoked EPSPs was examined in the presence of dopamine and 5-HT. As shown above, substance P consistently failed to modulate the amplitude of EIN-evoked EPSPs when applied in the presence of 5-HT alone (Fig. 2C,D). In 5-HT and dopamine, however, substance P significantly potentiated the EIN-evoked EPSP amplitude ( $n=4$ of 5; substance P in 5-HT and dopamine, $p<0.05$ ) (Fig. 4E,F). Again, because the postsynaptic substance $\mathrm{P}$-mediated potentiation of NMDA responses was blocked in the presence of dopamine and 5-HT (see above), the potentiation of the EPSP amplitude presumably reflected the presynaptic facilitatory effect of substance P. Dopamine thus reduces both the direct and interactive presynaptic inhibitory effects of 5-HT, to gate presynaptic tachykinin-mediated modulation.

\section{DISCUSSION}

Interactions between the colocalized modulators 5-HT and dopamine thus gate or break specific aspects of the tachykininmediated cellular, synaptic, and network modulation. Individual modulator effects are thus not only modulated by second-order "metamodulatory" interactions (Katz and Edwards, 1999), but these effects can also be modulated to result in dynamic changes in short- and long-term synaptic and network plasticity (for summary, see Fig. 5).

\section{5-HT inhibits substance P-mediated modulation}

5-HT blocked the induction of the long-term substance P-mediated burst frequency modulation and the presynaptic and postsynaptic modulation of glutamatergic synaptic transmission from network interneurons. The induction of the substance P-mediated network modulation requires the PKC-mediated potentiation of NMDA responses and an increase in intracellular $\mathrm{Ca}^{2+}$ levels in network neurons (Parker et al., 1998). 5-HT blocked the potentiation of NMDA responses by substance $\mathrm{P}$ and by PKC-activating phorbol esters. This inhibition of the NMDA receptor modulation, which presumably occurs through an effect on the activation or downstream effects of protein kinase $\mathrm{C}$ (Bhalla and Iyengar, 1999), thus provides a potential cellular locus for the inhibition of the network effects of substance P. A specific effect of 5-HT on the PKC-mediated induction phase of the burst frequency modulation was supported by the failure of 5-HT to reverse the network modulation once the protein synthesis-dependent maintenance phase had begun. 5-HT has a similar inhibitory effect on the induction, but not maintenance, of long-term potentiation in rat visual cortex (Edagawa et al., 2000).

The intracellular pathways through which 5-HT acts to inhibit the substance P-mediated network and NMDA receptor modulation are currently unknown. Protein phosphatase 1, 2A, or 2B, or PKA- or PKG-mediated pathways do not appear to contribute. The postsynaptic intracellular mechanisms underlying the inhibition of the substance P-mediated network modulation thus require additional analysis. These mechanisms could include an effect on the duration or strength of G-protein-mediated activation of intracellular pathways (Ferguson et al., 1996; Neer, 1997). In contrast, the inhibition of the presynaptic substance $\mathrm{P}$-mediated facilitation of glutamatergic synaptic transmission by 5-HT appears to depend on a PP2B-dependent mechanism that
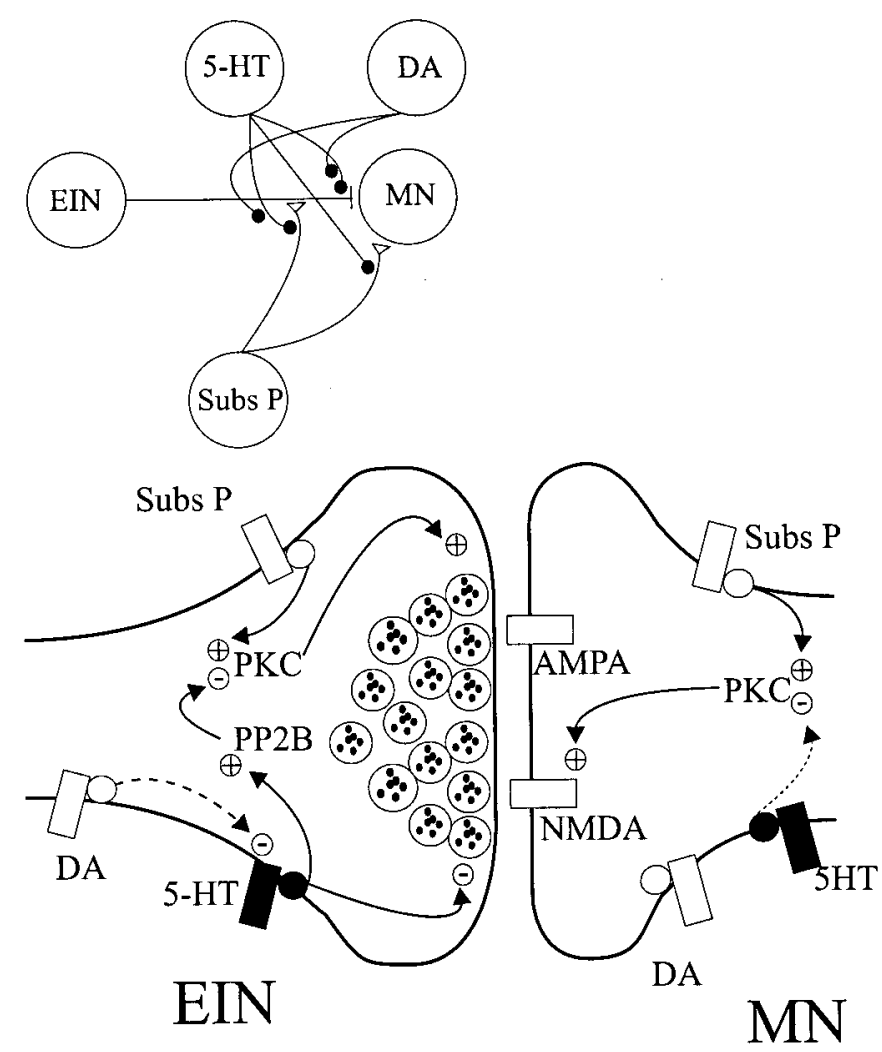

Figure 5. Summary of the presynaptic and postsynaptic effects of substance $\mathrm{P}(\operatorname{Subs} P)$ and the interactive effects of 5-HT and dopamine. The inset summarizes the direct and interactive presynaptic and postsynaptic effects of substance P, 5-HT, and dopamine $(D A)$ on EIN-evoked inputs in motor neurons $(M N)$. Open triangles represent potentiating effects, and filled circles represent inhibitory effects. The diagram represents a presynaptic EIN terminal that synapses onto a postsynaptic motor neuron. Substance P acts through PKC to presynaptically and postsynaptically potentiate glutamatergic inputs from the EIN. The postsynaptic effect is attributable to the specific potentiation of NMDA receptors, an effect that underlies the induction of the long-term network modulation. 5-HT acts directly on the presynaptic terminal to inhibit glutamatergic transmission and also inhibits the substance P-mediated presynaptic facilitation through a protein phosphatase $2 \mathrm{~B}$-mediated mechanism. Dopamine does not interact directly with substance $P$ but acts through unknown pathways to block the direct and interactive presynaptic inhibitory effects of 5-HT. Postsynaptically, 5-HT acts through an unknown mechanism to inhibit the substance $\mathrm{P}$ and $\mathrm{PKC}$-mediated potentiation of NMDA responses. Dopamine does not influence the postsynaptic effects of substance $\mathrm{P}$ or 5-HT. Because potentiated NMDA responses underlie the induction of the long-term burst frequency modulation by substance $\mathrm{P}$, dopamine will not gate long-term network plasticity. Dashed lines indicate unknown intracellular mechanisms.

presumably inhibits the proposed PKC-mediated pathway underlying this effect (Parker, unpublished observations).

\section{Interactive effects of dopamine}

Dopamine colocalizes with 5-HT in neurons in the ventromedial spinal plexus (Schotland et al., 1996). It acts additively with 5-HT to reduce the network burst frequency and the amplitude of the calcium-dependent afterhyperpolarization after action potentials (Schotland et al., 1995). Dopamine did not, however, share the inhibitory effect of 5-HT on the modulation evoked by exogenous substance $\mathrm{P}$ application. It may act synergistically with 5-HT in vivo, however, because it appears to inhibit endogenous tachykinin release. This is suggested by the ability of dopamine D2 receptor antagonists to elicit a long-term increase in the burst 
frequency that is blocked by the tachykinin antagonist Spantide II (Parker et al., 1998). Dopamine may thus tonically inhibit endogenous tachykinin release, whereas 5-HT inhibits tachykininmediated cellular and synaptic effects.

Although dopamine did not directly influence the effects of substance $\mathrm{P}$, by reducing the interactive presynaptic effect of 5-HT on glutamatergic synaptic transmission, it gated the substance P-mediated facilitation of glutamatergic inputs and thus indirectly facilitated the tachykinin modulation (Fig. 5). Dopamine did not, however, relieve the inhibition of the postsynaptic potentiation of NMDA responses and thus did not allow the long-term substance P-mediated network modulation to be induced. Dopamine and 5-HT independently or in interaction can thus gate or inhibit specific cellular, synaptic, or network effects of substance $\mathrm{P}$.

The gating of the presynaptic tachykinin-mediated modulation by dopamine contradicts the apparent D2 receptor-mediated inhibition of endogenous tachykinin release (Parker et al., 1998). If these opposing effects were to occur endogenously, mechanisms would be required to allow them to be evoked separately. These mechanisms could include concentration-dependent selection, possibly mediated through different dopamine receptor subtypes, which would allow effects to be recruited as a function of the activity of dopamine-containing neurons. Alternatively, modulator interactions may gate or inhibit the opposing effects of dopamine. Finally, dopamine release from separate dopaminecontaining systems (see below) may allow the spatial recruitment of separate modulatory effects.

\section{Factors affecting neuromodulator interactions in vivo}

The use of uptake blockers and breakdown inhibitors has demonstrated endogenous 5-HT, dopamine, and tachykinin release in the spinal cord. The effects evoked by breakdown inhibitors mimicked those evoked by exogenous modulator application (Christenson et al., 1989; Parker et al., 1998; Woolley et al., 2000). The interactions shown here have only been examined using exogenous modulator application. Endogenous interactions will need to be investigated, however, because endogenous modulator effects can differ to those evoked by exogenously (Blitz et al., 1999).

5-HT and dopamine are colocalized in ventromedial plexus neurons (Schotland et al., 1996). The colocalization of substance $\mathrm{P}$ with 5 -HT was reported to be limited, with only $\sim 4 \%$ of tachykinin-immunoreactive axons showing immunoreactivity to 5-HT (Van Dongen et al., 1986). The apparent colocalization of 5-HT and dopamine in all plexus neurons (Schotland et al., 1996) suggests that tachykinins may colocalize with 5-HT and dopamine to a greater extent. This, however, still requires direct examination. The evidence suggests that the plexus may contain three populations of neurons: one containing 5-HT, dopamine, and tachykinins; a second containing 5-HT and dopamine; and a third containing only tachykinins. The selective activation of these neurons by sensory or descending inputs (Schotland et al., 1996) could evoke different cellular, synaptic, or network effects. Activation of tachykinin neurons will evoke long-term network modulation, whereas the activation of dopamine and 5-HT neurons would block some or all of these effects.

The apparent colocalization of 5-HT and dopamine in all plexus neurons (Schotland et al., 1996) requires that mechanisms exist for their differential release if their gating and braking effects occur endogenously. Several mechanisms could allow this. First, 5-HT and dopamine may be released from separate vesicle populations. 5-HT is located in small clear and large dense-cored vesicles in the lamprey spinal cord (Franck et al., 1992) and dopamine in dense-cored vesicles (Schotland et al., 1996). Selective 5-HT release from small synaptic vesicles, and thus inhibition of tachykinin-mediated effects, could occur when plexus neurons are activated at low frequencies, whereas simultaneous 5-HT and dopamine release from large dense-cored vesicles could occur at higher frequencies (Bartfai et al., 1988). The proportions of 5-HT and dopamine released from dense-cored vesicles could also be influenced by the second-messenger-mediated regulation of release after vesicle fusion (Angleson et al., 1999) or the modulation of the relative proportions of 5-HT and dopamine contained in small or dense-cored vesicles (Whitnall, 1988). Finally, the interactive effects shown here could occur through the release of the modulators from sources other than the ventromedial plexus. Tachykinins could be released from primary afferents and local interneurons in the dorsal horn (Van Dongen et al., 1986) (Svensson, unpublished observations), 5-HT from primary afferents and descending reticulospinal axons (Brodin et al., 1986, 1988), and dopamine from cell bodies in the lateral cell column and around the central canal (Schotland et al., 1996). The potential variability of release sites further emphasizes the necessity of investigating effects evoked by endogenous modulator release from these pathways (Blitz et al., 1999).

\section{The role of the interactive effects of 5-HT and dopamine on substance $\mathbf{P}$ modulation}

Tachykinins profoundly affect the lamprey locomotor network. At physiological neuropeptide concentrations (Duggan, 1995), substance P irreversibly increases the burst frequency by $\sim 300 \%$ of control (Parker et al., 1998). The tachykinin modulation should thus only occur when it is appropriate to the ongoing behavior of the animal. The long-term network modulation may be related to migration, when lampreys swim long distances to upstream spawning grounds (Hardisty and Potter, 1971). The effects of 5-HT provide an endogenous mechanism for regulating the induction of the long-term network modulation, its pronounced inhibition effectively blocking short- and long-term substance P-mediated plasticity. The gating of the presynaptic but not postsynaptic potentiation of glutamatergic synaptic transmission by dopamine, however, provides a mechanism for allowing the short-term tachykinin-mediated facilitation of glutamatergic inputs to be evoked in the absence of the long-term network modulation.

Interactions between modulators (metamodulation; Katz and Edwards, 1999) can dynamically regulate long-term network plasticity (Kupfermann, 1991) (for review, see Brezina and Weiss, 1997; Katz and Edwards, 1999). The 5-HT-mediated modulation of the effects of substance $\mathrm{P}$ provides an example of spinal metamodulation. The effects of dopamine on the 5-HT-mediated presynaptic effects provide an example of a tertiary interaction, the modulation of metamodulation. Substance $\mathrm{P}$ affects a range of cellular and synaptic properties in the lamprey (Parker, 2001). This is a commonly recognized property of neuromodulators (Harris-Warrick et al., 1998; Katz, 1999). Although the functional role of distributed modulation is uncertain, it has been proposed as a mechanism for evoking flexible network plasticity (Sillar et al., 1997; Harris-Warrick et al., 1998). The interactions shown here support this conclusion. By selecting individual components from the modulatory repertoire of substance $\mathrm{P}$, dynamic changes can be evoked in short-term presynaptic and postsynaptic plasticity and consequently in the network output. 


\section{REFERENCES}

Abraham WC, Bear MF (1996) Metaplasticity: the plasticity of synaptic plasticity. Trends Neurosci 19:126-130.

Angleson JK, Cochilla AJ, Kilic G, Nussinovitch I, Betz WJ (1999) Regulation of dense core release from neuroendocrine cells revealed by imaging single exocytic events. Nat Neurosci 2:440-446.

Ayali A, Harris-Warrick RM (1998) Interaction of dopamine and cardiac sac modulatory inputs on the pyloric network in the lobster stomatogastric ganglion. Brain Res 794:155-161.

Bartfai T, Iverfeldt K, Fisone G, Srfozo P (1988) Regulation of the release of coexisiting neurotransmitters. Annu Rev Pharmaol Toxicol 28:285-310.

Bhalla US, Iyengar R (1999) Emergent properties of networks of biological signalling pathways. Science 283:381-387.

Blitz DM, Christie AE, Coleman MJ, Norris BJ, Marder E, Nusbaum MP (1999) Different proctolin neurons elicit distinct motor patterns from a multifunctional neuronal network. J Neurosci 19:5449-5463.

Brezina V, Weiss KR (1997) Analyzing the functional consequences of transmitter complexity. Trends Neurosci 20:538-543.

Brodin L, Buchanan JT, Hökfelt T, Grillner S, Verhofstad AAJ (1986) A spinal projection of 5-hydroxytryptamine neurons in the lamprey brainstem; evidence from combined retrograde tracing and immunohistochemistry. Neurosci Lett 67:53-57.

Brodin L, Buchanan JT, Hökfelt T, Grillner S, Rehfeld JF, Fray D, Verhofsted AAJ, Dockray GJ, Walsh JH (1988) Immunohistochemical studies of cholecystokinin like peptides and their relation to 5-HT, CGRP, and bombesin immunoreactivities in the brain stem and spinal cord of lampreys. J Comp Neurol: 271:1-18.

Buchanan JT (1993) Electrophysiological properties of identified classes of lamprey spinal neurons. J Neurophysiol 70:2313-2325.

Buchanan JT, Grillner S (1991) 5-Hydroxytryptamine depresses reticulospinal excitatory postsynaptic potentials in motoneurones of the lamprey. Neurosci Lett 112:71-74.

Christenson J, Franck J, Grillner S (1989) Increase in endogenous 5-hydroxytryptamine levels modulates the central network underlying locomotion in the lamprey spinal cord. Neurosci Lett 100:188-192.

Christenson J, Cullheim S, Grillner S, Hökfelt T (1990) 5-Hydroxytryptamine immunoreactive varicosities in the lamprey spinal cord have no synaptic specialisations: an ultrastructural study. Brain Res 512: 201-209.

Duggan AW (1995) Release of neuropeptides in the spinal cord. Prog Brain Res 104:197-224.

Edagawa Y, Saito H, Abe K (2000) The serotonin 5-HT2 receptorphospholipase $\mathrm{C}$ system inhibits the induction of long-term potentiation in the rat visual cortex. Eur J Neurosci 12:1391-1396.

Ferguson SS, Barak LS, Zhanj J, Caron MG (1996) G-protein coupled receptor regulation: role of G-protein-coupled receptor kinases and arrestins. Can J Physiol Pharmacol 74:1095-1110.

Franck J, Christenson J, Fried G, Cullheim S, Grillner S, Hökfelt T (1992) Subcellular distribution of serotonin in the lamprey spinal cord. Brain Res 589:8-54.

Hardisty MW, Potter IC (1971) The biology of lampreys, pp 127-207. London: Academic.

Harris-Warrick RM, Cohen AH (1985) Serotonin modulates the central pattern generator for locomotion in the isolated lamprey spinal cord. J Exp Biol 116:27-46.

Harris-Warrick RM, Marder E (1991) Modulation of neural networks for behavior. Annu Rev Neurosci 14:39-57.

Harris-Warrick RM, Johnson BR, Peck JH, Kloppenburg P, Ayali A, Skarbinski J (1998) Distributed effects of dopamine modulation in the crustacean pyloric network. Ann NY Acad Sci 860:155-167.

Herzig S, Neumann J (2000) Effects of serine/threonine protein phosphatases on ion channels in excitable membranes. Physiol Rev 80:173-210.
Katz PS (1999) Beyond neurotransmission (Katz PS, ed). New York: Oxford UP.

Katz PS, Edwards DH (1999) Metamodulation: the control and modulation of neuromodulation. In: Beyond neurotransmission (Katz PS, ed), pp 349-382. New York: Oxford UP.

Kemnitz CP (1997) Dopaminergic modulation of spinal neurons and synaptic potentials in the lamprey spinal cord. J Neurophysiol 77:289-298.

Kupfermann I (1991) Functional studies of cotransmission. Physiol Rev 71:683-732.

McPherson DR, Kemnitz CP (1994) Modulation of fictive swimming and motoneuron physiology by dopamine, and its immunocytochemical localization in the spinal cord. Neurosci Lett 166:23-26.

Neer EJ (1997) Intracellular signalling: turning down G-protein signals. Curr Biol 7:31-33.

Parker D (2000) Presynaptic and interactive peptidergic modulation of reticulospinal synaptic inputs in the lamprey. J Neurophysiol 83:2497-2507.

Parker D (2001) Spinal cord plasticity: independent and interactive effects of neuromodulator and activity-dependent plasticity. Mol Neurobiol 22: 55-80.

Parker D, Grillner S (1998) Cellular and synaptic modulation underlying substance P-mediated plasticity of the lamprey locomotor network. J Neurosci 18:8095-8110.

Parker D, Svensson E, Grillner S (1997) Substance P modulates sensory action potentials in the lamprey via a protein kinase $\mathrm{C}$-mediated reduction of voltage-dependent potassium conductances. Eur J Neurosci 9:2064-2076.

Parker D, Zhang W, Grillner S (1998) Substance P modulates NMDA responses and causes long-term protein synthesis-dependent modulation of the lamprey locomotor network. J Neurosci 18:4800-4813.

Schotland J, Supliakov O, Wikström M, Brodin L, Srinivasan M, You Z, Herrera-Marschitz M, Z hang W, Hökfelt T, Grillner S (1995) Control of lamprey locomotor neurons by colocalized monoamine transmitters. Nature 374:266-268.

Schotland JL, Shupliakov O, Grillner S, Brodin L (1996) Synaptic and nonsynaptic monoaminergic neuron systems in the lamprey spinal cord. J Comp Neurol 372:229-244.

Sillar KT, Kiehn O, Kudo N (1997) Chemical modulation of vertebrate motor circuits. In: Neurons, networks, and motor behaviour (Stein PSG, Grillner S, Selverston AI, Stuart DG, eds), pp 183-194. Cambridge, MA: MIT.

Svensson E, Parker D, Wikström M, Grillner S (1997) Substance P induces oscillations of spinal motoneurones in lamprey. Soc Neurosci Abstr 22:384.10.

Van Dongen PA, Theodorsson-Norheim E, Brodin E, Hökfelt T, Grillner S, Peters A, Cuello AC, Forssman WG, Reinecke M, Singer EA Lazarus LH (1986) Immunohistochemical and chromatographic studies of peptides with tachykinin like immunoreactivity in the central nervous system of the lamprey. Peptides 7:297-313.

Wald U, Selzer M (1981) The inulin space of the lamprey spinal cord. Brain Res 208:113-122.

Wallén P, Buchanan JT, Grillner S, Hill RH, Christenson J, Hökfelt T (1989) Effects of 5-hydroxytryptamine on the afterhyperpolarisation, spike frequency regulation, scillatory membrane properties in lamprey spinal cord nerves. J Neurophysiol 61:759-768.

Whitnall MH (1988) Distributions of pro-vasopressin expressing and pro-vasopressin deficient CRH neurons in the paraventricular hypothalamic nucleus of the colchicine-treated normal and adrenalectomized rats. J Comp Neurol 275:13-28.

Wood DE (1995) Neuromodulation of rhythmic motor patterns in the blue crab Callinectes sapidus by amines and the peptide proctolin. J Comp Physiol 177:335-349.

Woolley JD, Svensson E, Grillner S (2000) Modulatory effects of endogenously released dopamine in the lamprey. Soc Neurosci Abstr 26 60.6 . 